\title{
DUKUNGAN SUAMI KEPADA ISTRI DALAM UPAYA PEMBERIAN ASI DI RUMAH SAKIT PANTI WILASA CITARUM SEMARANG
}

\author{
Ester Ratnaningsih ${ }^{1}$ \\ 1.Prodi Pendidikan Profesi Bidan Universitas Respati Yogyakarta \\ Email: esteratna@gmail.com
}

\begin{abstract}
ABSTRAK
ASI adalah makanan terbaik yang harus diberikan kepada bayi karena terkandung semua zat gizi yang dibutuhkan untuk pertumbuhan dan perkembangan bayi. Salah satu faktor yang mempengaruhi keberhasilan ASI Eksklusif adanya dukungan suami yang dapat membuat ibu merasa tenang sehingga memperlancar produksi ASI. Penelitian ini bertujuan untuk mengetahui hubungan dukungan suami dalam upaya pemberian ASI dengan keberhasilan ASI Eksklusif di Rumah Sakit Panti Wilasa Citarum Semarang. Penelitian ini menggunakan metode korelasi dengan pendekatan cross-sectional. Sampel berjumlah 36 ibu nifas primipara yang diambil menggunakan teknik accidental sampling. Data dianalisa menggunakan analisa deskriptif, korelasi menggunakan Chi Square. Penelitian ini menghasilkan temuan bahwa ibu primipara yang mendapat dukungan suami secara aktif dalam pemberian ASI sebesar 41,7 \%, meliputi dukungan emosional sebesar 38,9\%, dukungan informasi sebesar 52,8 \%, dukungan fisik sebesar 44,4\% dan dukungan penilaian sebesar $38,9 \%$. Ibu yang berhasil memberikan ASI Eksklusif sebesar 33,3\%. Ada hubungan dukungan suami dalam pemberian ASI dengan keberhasilan ASI Eksklusif di Rumah Sakit Panti Wilasa Citarum Semarang $(\mathrm{p}=0.03)$. Disarankan kepada Rumah Sakit Panti Wilasa Citarum bisa meningkatkan dukungan suami terhadap pemberian ASI melalui program pembentukan kelas ayah dalam upaya persiapan menjadi ayah ASI.
\end{abstract}

Kata Kunci: Dukungan suami, ASI Eksklusif, Primipara

\section{ABSTRACT}

Breast milk is the best food that should be given to infants since it contains all the nutrients needed for growth and development of infants. One of the factors that influence the success of exclusive breastfeeding is the support of a husband that can make a mother feel calm so as to facilitate the production of breast milk. This study aims to determine the relationship between husband support in breastfeeding efforts and the success of exclusive breastfeeding at Panti Wilasa Cita rum Ho spital Semarang. This study used a correlation method with a cross-sectional approach. The study samples consisted of 36 primiparous postpartum women selected using accidental sampling technique. Data were analyzed using descriptive analysis, correlation was tested using Chi Square. The study findings showed that primiparous $41.7 \%$ women received active husband support in breastfeeding by, including emotional support by $38.9 \%$, information support by $52.8 \%$, physical support by $44.4 \%$ and assessment support for 38.9\%. 33.3\% women managed to give exclusive breastfeeding. There was a relationship between husband's support in breastfeeding with the success of exclusive breastfeeding at Panti Wilasa Citarum Hospital Semarang $(p=0.03)$. It is recommended that Panti Wilas a Citarum Hospital could increase the husband support in breastfeeding through the establishment of father class program as an effort to prepare husband to become a breastfeeding father.

Keywords: Husband support, Exclusive breastfeeding, Primiparous women

\section{PENDAHULUAN}

Keberhasilan pembangunan nasional ditentukan oleh adanya sumber daya manusia (SDM) yang berkualitas, dicirikan dengan fisik yang tangguh, kesehatan yang prima dan menguasai ilmu pengetahuan serta teknologi. Salah satu prioritas pembangunan nasional saat ini adalah meningkatkan derajat kesehatan 
masyarakat Indonesia dengan indikator utamanya adalah angka kematian bayi atau Infant Mortality Rate (IMR). Salah satu faktor yang berkaitan dengan angka kematian bayi adalah status gizi bayi. Salah satu langkah penting untuk peningkatan status gizi bayi adalah dengan pemberian makanan pertama yang berkualitas dan optimal. ASI merupakan makanan dan minuman utama pada bayi usia 0-6 bulan karena ASI mudah dicerna dan langsung terserap oleh bayi. Jika proses laktasi dilakukan dengan baik segera setelah lahir, pemberian ASI saja sampai usia 6 bulan dapat mencukupi nutrisi bayi. ASI sebagai satu-satunya nutrisi bayi sampai usia enam bulan dianggap sangat berperan penting untuk tumbuh kembang anak (Kemenkes, 2012).

ASI adalah makanan terbaik yang harus diberikan kepada bayi karena didalamnya terkandung hampir semua zat gizi yang dibutuhkan oleh bayi. ASI merupakan pilihan terbaik bagi bayi karena didalamnya mengandung antibodi dan lebih dari 100 jenis zat gizi yaitu AA, DHA, taurin dan spingomyelin. Kolostrum ialah ASI yang disekresi dari hari pertama sampai hari ketiga atau keempat dengan warna kekuningkuningan yang berfungsi untuk membersihkan mekonium dari usus bayi baru lahir dan membersihkan saluran pencernaan bayi yang akan datang serta mengandung zat kekebalan terutama immunoglobulin A (Ig A) untuk melindungi bayi dari berbagai penyakit infeksi seperti diare (Yuliarti, 2010).

Pemberian kolostrum secara awal pada bayi dan pemberian ASI secara terus menerus merupakan perlindungan yang terbaik pada bayi karena bayi dapat terhindar dari penyakit dan memiliki zat anti kekebalan $10-17$ kali daripada susu matur (Saleha, 2009). Pemberian ASI sangat perlu diberikan secara eksklusif sampai umur 6 (enam) bulan dan dapat dilanjutkan sampai anak berumur 2 (dua) tahun.(Kemenkes, 2012)

Secara nasional cakupan ASI Eksklusif di Indonesia berfluktuasi selama 6 tahun terakhir. Persentase anak berumur di bawah 6 bulan yang mendapat ASI eksklusif meningkat dalam 5 tahun terakhir, dari 42 persen pada SDKI 2012 menjadi 52 persen pada SDKI 2017. Persentase anak yang tidak mendapat ASI naik dari 8 persen pada SDKI 2012 menjadi 12 persen pada SDKI 2017
(SDKI 2017). Kendala dalam pencapaian ASI Eksklusif, alasan yang menjadi penyebab kegagalan praktek ASI eksklusif bermacammacam seperti budaya memberikan makanan pralaktal, memberikan tambahan susu formula karena ASI tidak keluar, menghentikan pemberian ASI Eksklusif karena bayi atau ibu sakit, ibu harus bekerja, dan ibu ingin mencoba susu formula (Kemenkes, 2011).

Berdasarkan hasil Laporan Puskesmas Kota Semarang tahun 2018, pemberian ASI Ekslusif pada bayi umur 0-6 bulan sejumlah 10.733 bayi atau $68,22 \%$. Pemberian ASI Eksklusif pada bayi 0-6 bulan di Kota Semarang telah mencapai target Renstra Kota Semarang $(65,20 \%)$. Sedangkan bila dibandingkan dengan pencapaian tahun 2017 ada peningkatan dari $67,33 \%$ menjadi $68,22 \%$ pada tahun 2018, hal ini disebabkan karena adanya komitmen petugas kesehatan untuk membantu ibu yang mengalami kesulitan dalam menyusui, ada peningkatan pengetahuan ibu tentang manfaat menyusui dan cara menyusui yang tepat dan dukungan dari keluarga. (Profil Kesehatan Kota Semarang, 2018)

Rendahnya keberhasilan ASI eksklusif di Indonesia merupakan masalah yang membutuhkan penanganan yang serius, mengingat betapa pentingnya ASI bagi status kesehatan bayi yang nantinya akan mempengaruhi kualitas hidup bayi. Menurut Arora $d k k$ salah satu faktor yang mendukung ibu menyusui adalah adanya dukungan keluarga. Dukungan dokter, bidan, atau petugas kesehatan lainnya, teman atau kerabat dekat sangat dibutuhkan terutama untuk ibu yang baru pertama kali hamil. Menurut Roesli (2012), rendahnya pencapaian ASI Eksklusif tersebut juga terkait dengan peran suami yang memiliki andil yang cukup besar dengan kondisi psikis ibu menyusui.

Dukungan suami sangat berarti dalam menghadapi tekanan ibu nifas dalam menjalani proses menyusui. Dukungan suami dan keluarga membuat ibu merasa tenang sehingga memperlancar produksi ASI. Agar proses menyusui lancar, diperlukan breastfeeding father yaitu ayah membantu ibu agar bisa menyusui dengan nyaman sehingga ASI yang dihasilkan maksimal (Nur Khasanah, 2011). Penelitian Destriatania (2010) juga mengungkapkan bahwa praktik pemberian ASI 
eksklusif cenderung 1,4 kali lebih tinggi pada ayah yang memiliki pengetahuan postnatal tinggi dibandingkan ayah yang memiliki pengetahuan postnatal rendah.

Berdasarkan studi pendahuluan yang dilakukan oleh peneliti pada Bulan Juni 2019 di Rumah Sakit Panti Wilasa Citarum Semarang bahwa rumah sakit senantiasa mendukung keberhasilan program ASI Ekslusif. Berdasarkan hasil wawancara terhadap 8 orang ibu primipara, hanya 3 yang telah melewati masa enam bulan dan sukses memberikan ASI Eksklusif, sedangkan 5 lainnya tidak memberikan ASI Eksklusif pada bayinya. Dari 5 orang ibu yang tidak bisa memberikan ASI Eksklusif, sebanyak 4 orang menyatakan bahwa suami tidak membantu ibu saat ibu sedang menyusui bayinya, suami takut ikut serta merawat bayinya. Berdasarkan fenomena dan uraian diatas, peneliti tertarik untuk melakukan penelitian dengan judul "Dukungan Suami Kepada Istri Dalam Upaya Pemberian ASI di Rumah Sakit Panti Wilasa Citarum Se marang”.

\section{METODE}

Penelitian ini dilakukan dengan rancangan cross sectional dengan variabel independen adalah dukungan suami terhadap pemberian ASI, sedangkan variabel dependennya adalah keberhasilan ASI Eksklusif. Karakteristik responden yang diteliti antara lain : ibu nifas primipara yang datang ke Poli Kebidanan dan Kandungan Rumah Sakit Panti Wilasa Citarum Semarang. Populasi dalam penelitian ini adalah semua ibu primipara yang telah melewati ASI Eksklusif 6 bulan yang datang periksa di Poli Kebidanan dan Kandungan Rumah Sakit Panti Wilasa
Citarum Semarang Kota Semarang. Teknik pengambilan sampel yang digunakan dalam penelitian ini adalah dengan teknik accidental sampling. Jumlah sampel yang digunakan dalam penelitian ini adalah 36 orang, dan waktu pengambilan sampel dari tanggal $1-31$ Juli 2019.

Alat yang digunakan dalam penelitian ini adalah kuesioner data demografi, kuesioner penilaian dukungan suami yang didapat dari ibu nifas meliputi dukungan emosional, informasi, fisik, penilaian dan kuesioner keberhasilan ASI Eksklusif. Data dianalisis secara univariat dengan menggunakan distribusi frekuensi dan persentase, analisis bivariat dengan menggunakan uji Chi Square. Variabel yang dianalisis secara univariat dalam penelitian ini adalah umur ibu, umur suami, tingkat pendidikan suami, pekerjaan suami. Analisis Bivariat dalam penelitian ini, menggunakan uji statistik non parameter teknik analisis bivariat dengan uji Chi Square.

\section{HASIL}

\section{Karakteristik Responden}

Responden yang terlibat di dalam penelitian ini merupakan ibu primipara yang telah melalui masa ASI Eksklusif selama 6 bulan sebanyak 36 orang. Ibu Nifas primipara yang sedang periksa di Poli Kebidanan dan Kandungan Rumah Sakit Panti Wilasa Citarum Semarang yang menjadi responden penelitian ini memiliki berbagai karakteristik. Tabel 1 menunjukkan sebaran responden berdasarkan karakteristik umur ibu, umur suami, pendidikan terakhir ibu, pendidikan terakhir suami, pekerjaan ibu, pekerjaan suami.

\section{Tabel 1 Dis tribusi Frekuensi dan Persentase Data Demografi Responden dan Suami}

\begin{tabular}{|c|c|c|}
\hline Data Demografi & $\mathbf{N}$ & Persentase \\
\hline \multicolumn{3}{|l|}{ Umur Ibu } \\
\hline$<20$ tahun & 2 & $5,6 \%$ \\
\hline 20-25 tahun & 29 & $80,6 \%$ \\
\hline 26-30 tahun & 5 & $13,9 \%$ \\
\hline \multicolumn{3}{|l|}{ Umur Suami } \\
\hline 20-25 tahun & 15 & $41,7 \%$ \\
\hline 26-30 tahun & 12 & $33,3 \%$ \\
\hline 31-35 tahun & 9 & $25,0 \%$ \\
\hline \multicolumn{3}{|l|}{ Tingkat Pendidikan Ibu } \\
\hline Rendah (SD, SMP) & 4 & $11,1 \%$ \\
\hline Menengah (SMA) & 21 & $58,3 \%$ \\
\hline Tinggi (Perguruan Tinggi) & 11 & $30,6 \%$ \\
\hline
\end{tabular}




\begin{tabular}{lcc}
\hline Tingkat Pendidikan Suami & & \\
Rendah (SD, SMP) & 2 & $5,6 \%$ \\
Menengah (SMA) & 17 & $47,2 \%$ \\
Tinggi (Perguruan Tinggi) & 17 & $47,2 \%$ \\
\hline Status Pekerjaan Ibu & & \\
Bekerja & 16 & $44,4 \%$ \\
Tidak Bekerja & 20 & $55,6 \%$ \\
\hline Status Pekerjaan Suami & & \\
Pegawai Swasta & 17 & $47,2 \%$ \\
Buruh Pabrik & 13 & $36,1 \%$ \\
Pegawai Negeri & 6 & $16,7 \%$ \\
\hline
\end{tabular}

Berdasarkan kelompok umur, sebagian besar responden berada pada kelompok umur ibu dengan usia 20 -25 tahun yaitu 29 orang ( $80,6 \%$ ) dari total 36 orang responden, sedangkan umur suami terbanyak pada rentang usai 20-25 tahun sebanyak 15 orang $(41,7 \%)$. Berdasarkan tingkat pendidikan ibu, maka terbanyak adalah pendidikan terakhir ibu adalah menengah (SMA), yaitu 21 orang (58,3 $\%)$, sedangkan tingkat pendidikan suami terbanyak pendidikan menengah dan perguruan tinggi masing- masing sama yaitu sebanyak 17 orang $(47,2 \%)$. Berdasarkan status pekerjaan, ibu tidak bekerja atau sebagai

Tabel 2 Distribusi Frekuensi dan Persentase Dukungan Suami ke pada Istri dalam Upaya Pemberian ASI $(\mathbf{n}=36)$

\begin{tabular}{lcc}
\hline Dukungan Suami & $\mathbf{N}$ & $\begin{array}{c}\text { Persentase } \\
(\mathbf{\%})\end{array}$ \\
\hline Mendukung & & $41,7 \%$ \\
Tidak Mendukung & 15 & $58,3 \%$ \\
\hline Total & 21 & 100 \\
\hline
\end{tabular}

Tabel 2 menunjukkan bahwa sebanyak 15 ibu nifas primipara mendapatkan dukungan dari suami dalam pemberian ASI. Hasil penelitian ini menunjukkan juga sebagian besar suami tidak mendukung istri dalam pemberian ASI sebesar 58,3\%.

Tabel 3 Distribusi Frekuensi dan Persentase Dukungan Emosional Suami ke pada Istri dalam Upaya Pemberian ASI $(n=36)$

\begin{tabular}{lrc}
\hline $\begin{array}{l}\text { Dukungan } \\
\text { Emosional }\end{array}$ & N & Persentasi (\%) \\
\hline Mendukung & 14 & 38,9 \\
Tidak Mendukung & 22 & 61,1 \\
\hline Total & 36 & 100 \\
\hline \multicolumn{2}{c}{ Sebanyak 38,9 \% ibu nifas primipara } & frekuensi dan persentase item-item dukungan \\
mendapatkan dukungan emosional suami. & emosional suami dalam upaya pemberian ASI \\
Dukungan emosional berupa memberikan rasa & Eksklusif dapat dilihat pada tabel 4 berikut.
\end{tabular}

nyaman kepada ibu saat menyusui dan perasaan dicintai. Rincian mengenai sebaran

Tabel 4 Distribusi Frekuensi dan Persentase Item Dukungan Emosional Suami dalam Upaya Pemberian ASI $(\mathbf{n}=36)$ 


\begin{tabular}{lcc}
\hline \multicolumn{1}{c}{ Item Pernyataan } & Ya & Tidak \\
\hline $\begin{array}{l}\text { Suami menggendong bayi } \\
\text { untuk disusui }\end{array}$ & 17 & 19 \\
\hline $\begin{array}{l}\text { Suami menolong is tri untuk } \\
\text { menyendawakan bayi }\end{array}$ & $(47 \%)$ & $(53 \%)$ \\
\hline $\begin{array}{l}\text { Suami memberi kata pujian } \\
\text { setiap ibu selesai menyusui }\end{array}$ & $(69 \%)$ & $(31 \%)$ \\
\hline $\begin{array}{l}\text { Suami menyarankan ibu } \\
\text { tidak usah takut menyusui } \\
\text { karena menyebabkan } \\
\text { perubahan bentuk tubuh }\end{array}$ & 21 & 15 \\
\hline $\begin{array}{l}\text { Suami bersikap mesra } \\
\text { selama ibu menyusui } \\
\text { bayinya }\end{array}$ & $18 \%)$ & $(42 \%)$ \\
\hline $\begin{array}{l}\text { Suami memberi suasana } \\
\text { tenang saat ibu menyusui } \\
\text { bayinya }\end{array}$ & $(50 \%)$ & 18 \\
\hline
\end{tabular}

Sebanyak 25 ibu primipara dari total 36 responden menyatakan suami menolong ibu untuk menyendawakan bayi. Sebaliknya,

Tabel 5. Distribusi Frekuensi dan Persentase Dukungan Informasi Suami kepada Istri dalam Upaya Pemberian ASI $(n=36)$

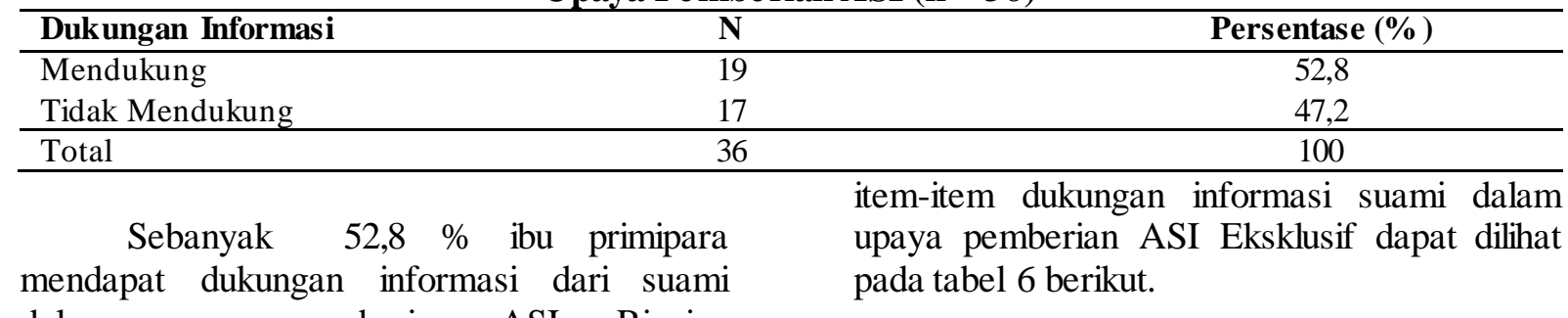

terdapat 24 ibu yang suaminya tidak memberikan suasana tenang saat ibu menyusui bayinya. dalam upaya pemberian ASI. Rincian mengenai sebaran frekuensi dan persentase

Tabel 6. Distribusi fre kuensi dan persentase item Dukungan Informasi Suami dalam upaya pemberian ASI

\begin{tabular}{lcc} 
& $(\mathbf{n}=\mathbf{3 6 )}$ & \\
\hline \multicolumn{1}{c}{ Item Pernyataan } & Ya & Tidak \\
\hline $\begin{array}{l}\text { Suami memberi bacaan tentang ASI } \\
\text { eksklusif sepertibuku dan majalah. }\end{array}$ & 19 & 17 \\
\hline $\begin{array}{l}\text { Suami memberi informasi pada ibu } \\
\text { tentang ASI Eksklusif }\end{array}$ & $(53 \%)$ & $(47 \%)$ \\
\hline $\begin{array}{l}\text { Suami mencari informasi tentang ASI } \\
\text { Eksklusif }\end{array}$ & 17 & 19 \\
\hline $\begin{array}{l}\text { Suami mengantar ibu konsultasipada } \\
\text { tenaga kesehatan tentang pemberian }\end{array}$ & 21 & 15 \\
ASI & $(58 \%)$ & $(42 \%)$ \\
\hline $\begin{array}{l}\text { Suami melarang ibu bertanya pada } \\
\text { siapapun tentang pemberian ASI }\end{array}$ & 31 & 5 \\
\hline $\begin{array}{l}\text { Suami mengingatkan ibu untuk } \\
\text { mengikuti anjuran tenaga kesehatan }\end{array}$ & $(86 \%)$ & $(14 \%)$ \\
tentang menyusui & 4 & 32 \\
\hline
\end{tabular}

Tabel 6 menunjukkan hanya 58,3\% suami yang mencari informasi tentang ASI Eksklusif, sebaliknya masih ada $11,1 \%$ suami

Tabel 7 Dis tribusi Frekuensi dan Persentase Dukungan Fis ik Suami ke pada Istri dalam Upaya Pemberian ASI 


\begin{tabular}{llc} 
& $(\mathbf{n = 3 6 )}$ & \\
\hline Dukungan Fisik & $\mathbf{N}$ & Persentase (\%) \\
\hline Mendukung & 16 & 44,4 \\
Tidak Mendukung & 20 & 55,6 \\
\hline Total & 36 & 100 \\
\hline
\end{tabular}

Sebanyak $44,4 \%$ ibu primipara mendapatkan dukungan fisik suami kepada istri dalam upaya pemberian ASI. Rincian mengenai sebaran frekuensi dan persentase item-item dukungan fisik suami dalam upaya pemberian ASI Eksklusif dapat dilihat pada tabel 8 berikut.

Tabel 8 Distribusi Frekuensi dan Persentase Item Dukungan Fisik Suami dalam upaya pe mberian ASI Eksklusif

\begin{tabular}{lcc}
\multicolumn{1}{c}{ Item Pernyataan } & & \\
\hline & Ya & Tidak \\
\hline Suami ikut merawat bayi seperti mengganti popok & 14 & 22 \\
& $(39 \%)$ & $(61 \%)$ \\
\hline Suami menggendong bayi jika menangis & 14 & 22 \\
& $(39 \%)$ & $(61 \%)$ \\
\hline Suami melakukan pekerjaan rumah tangga saat ibu & 15 & 21 \\
sedang menyusui & $(42 \%)$ & $(58 \%)$ \\
\hline Suami mau mengambilkan minum untuk ibu selagi & 26 & 10 \\
ibu menyusui & $(72 \%)$ & $(28 \%)$ \\
\hline Suami mau mengambilkan makan untuk ibu selagi & 21 & 15 \\
ibu menyusui & $(58 \%)$ & $(42 \%)$ \\
\hline Suami memperhatikan jenis dan jumlah makanan & 17 & 19 \\
ibu selama menyusui & $(47 \%)$ & $(53 \%)$ \\
\hline
\end{tabular}

Sebanyak $41,6 \%$ suami dari total 36 responden menyatakan suami membantu melakukan pekerjaan rumah tangga saat ibu sedang menyusui. Sebaliknya, terdapat 10 suami yang tidak mau mengambilkan minum selagi ibu menyusui.

Tabel 9 Distribusi Frekuensi dan Persentase Dukungan Penilaian Suami ke pada Istri dalam Upaya Pemberian ASI

$(n=36)$

\begin{tabular}{lcc}
\hline Dukungan Penilaian & N & Persentasi (\%) \\
\hline Mendukung & 14 & 38,9 \\
Tidak Mendukung & 22 & 61,1 \\
\hline Total & 36 & 100 \\
\hline
\end{tabular}

Sebanyak $61,1 \%$ responden tidak mendapatkan dukungan penilaian dari suami dalam upaya pemberian ASI. Rincian mengenai sebaran frekuensi dan persentase item-item dukungan penilaian suami dalam upaya pemberian ASI Eksklusif dapat dilihat pada tabel 10 berikut.

Tabel 10 Distribusi fre kuensi dan Persentase Item Dukungan Penilaian Suami dalam upaya pemberian ASI Eksklusif

\begin{tabular}{lcc}
\multicolumn{3}{c}{$(\mathbf{n = 3 6 )}$} \\
\hline \multicolumn{1}{c}{ Item Pernyataan } & Ya & Tidak \\
\hline Suami mendorong ibu untuk segera & 28 & 8 \\
menyusui bayinya segera setelah lahir & $(78 \%)$ & $(22 \%)$ \\
\hline
\end{tabular}




\begin{tabular}{lcc}
\hline Suami memperhatikan kebutuhan gizi ibu & 27 & 9 \\
& $(75 \%)$ & $(25 \%)$ \\
\hline Ketika jumlah ASI sedikit suami & 10 & 26 \\
menyarankan ibu memberi susu formula & $(28 \%)$ & $(72 \%)$ \\
\hline Suami memotivasi ibu ketika ASI tidak & 15 & 21 \\
keluar & $(42 \%)$ & $(58 \%)$ \\
\hline Suami menyarankan ibu tetap memberikan & 18 & 18 \\
ASI eksklusif & $(50 \%)$ & $(50 \%)$ \\
\hline Suami menyarankan ibu memberi ASI & 21 & 15 \\
sesuai kebutuhan bayi & $(58 \%)$ & $(42 \%)$ \\
\hline
\end{tabular}

Berdasar tabel 10 didapatkan $77,7 \%$ suami mendorong ibu untuk segera menyusui bayinya segera setelah lahir, sebaliknya masih

Tabel 11. Distribusi fre kuensi dan terdapat $27,8 \%$ suami yang menyarankan ibu memberi susu formula ketika ASI sedikit.

b. Keberhasilan ASI Eksklusif persentase Keberhasilan ASI Eksklusif $(\mathbf{n}=36)$

\begin{tabular}{lcc}
\hline $\begin{array}{l}\text { Keberhasilan ASI } \\
\text { Eksklusif }\end{array}$ & N & Persentase (\%) \\
\hline Berhasil & 12 & 33,3 \\
Tidak Berhasil & 24 & 66,7 \\
\hline Total & 36 & 100 \\
\hline
\end{tabular}

Hasil penelitian tentang Keberhasilan primipara yang berhasil menyelesaikan ASI Eksklusif selama 6 bulan.

ASI Eksklusif menunjukkan hanya 33,3 \% ibu

\section{Hasil Analisis Bivariat}

Tabel 12 Hubungan Dukungan Suami kepada Istri dengan Keberhasilan ASI Eksklusif di Rumah Sakit Panti Wilasa Citarum Semarang $(n=36)$

\begin{tabular}{|c|c|c|c|c|}
\hline \multirow{2}{*}{$\begin{array}{l}\text { Dukungan } \\
\text { Suami }\end{array}$} & \multicolumn{2}{|c|}{ Keberhasilan ASI Eksklusif } & \multirow{2}{*}{$\begin{array}{l}\text { Jumlah } \\
\text { f (\%) }\end{array}$} & \multirow[b]{2}{*}{$\rho$} \\
\hline & $\begin{array}{c}\text { Tidak Berhasil } \\
\mathrm{f}(\%)\end{array}$ & $\begin{array}{l}\text { Berhasil } \\
\mathrm{f}(\%)\end{array}$ & & \\
\hline Tidak & $17(80,9 \%)$ & $4(19,1 \%)$ & $21(100 \%)$ & \\
\hline Mendukung & & & & 0.03 \\
\hline Mendukung & $7(46,6 \%)$ & $8(53,4 \%)$ & $15(100 \%)$ & \\
\hline Jumlah & 24 & 12 & $36(100 \%)$ & \\
\hline
\end{tabular}

Berdasarkan tabel 12 hasil penelitian menunjukkan bahwa dari 15 ibu primipara yang mendapat dukungan dari suami, sebesar 8 orang $(53,4 \%)$ yang berhasil menyusui secara ASI Eksklusif. Hasil penelitian juga menunjukkan dari 21 ibu primipara yang tidak mendapat dukungan suami ada 4 orang $(19,1 \%)$ yang berhasil menyusui secara eksklusif.

Berdasarkan uji statistik tersebut didapatkan hasil nilai $\rho$ value 0.03 ini berarti $\rho$ value lebih kecil dari taraf signifikan 5\% $(0.03<0.05)$ sehingga hasil yang di dapat $\mathrm{H}_{\mathrm{a}}$ diterima. Jadi, hasil analisis menunjukkan terdapat hubungan antara dukungan suami dalam upaya pemberian ASI dengan keberhasilan ASI Eksklusif di Rumah Sakit Panti Wilasa Citarum Semarang.

\section{PEMBAHASAN}

Berdasarkan hasil yang diperoleh, maka pembahasan ini dilakukan untuk menjawab tujuan penelitian sebagai berikut:

\section{Karakte ristik Demografi Responden}

Responden dalam penelitian ini adalah ibu- ibu primipara yang periksa di Poli Kebidanan dan Kandungan Rumah Sakit Panti Wilasa Citarum Semarang. Jumlah responden yang berpartipasi dalam penelitian ini adalah 36 orang ibu primipara. Berdasarkan Tabel 1 dapat diketahui bahwa sebagian besar responden berumur 20-25 tahun dengan proporsi $80,6 \%$, sedangkan suami sebagian besar berusia 20-25 tahun sebesar 41,7\%. Pada usia 20-25 tahun merupakan usia dalam reproduksi sehat, dimana pada usia tersebut kemampuan laktasi lebih baik, dibandingkan ibu yang berumur $>35$ tahun, suplai jumlah ASI cenderung tidak cukup karena produksi ASI mengalami sedikit penurunan. 
Berdasarkan status pekerjaan, responden pada penelitian ini tidak bekerja atau sebagai. Ibu rumah tangga sebesar 55,6\%, sedangkan ibu yang bekerja sebanyak $44,4 \%$. Peluang ibu dalam keberhasilan ASI eksklusif juga dipengaruhi oleh pekerjaan ibu. Ibu bekerja cenderung menjadi penyebab kegagalan ASI eksklusif. Ibu bekerja mempunyai waktu terbatas untuk merawat bayinya dan tidak dapat sehari penuh terlibat dalam pengasuhan bayi. Kondisi seperti ini perlu ada dukungan suami untuk bekerja sama dalam hal pengasuhan bayi. Selama ibu berada di tempat kerja, suami dapat mengambil alih pekerjaan rumah tangga, sehingga sesampainya di rumah ibu berkesempatan untuk memberikan ASI tanpa harus direpotkan lagi dengan pekerjaan rumah tangga. Studi Liubai LI di Cina telah membuktikan, ibu yang tidak bekerja berpeluang 1,2 kali untuk menyusui eksklusif dibanding ibu yang bekerja, karena ibu yang tidak bekerja mempunyai waktu lebih banyak bersama bayi, dibandingkan ibu yang bekerja.

Hasil penelitian pekerjaan suami adalah sebagai pegawai swasta sebanyak $47,2 \%$, buruh pabrik sebanyak $36,1 \%$ dan pegawai negeri sebanyak $16,7 \%$. Pekerjaan suami merupakan confounder yang mempengaruhi dukungan suami sekaligus mempengaruhi pemberian ASI eksklusif. Kesibukan suami dalam mencari nafkah merupakan salah satu hambatan suami untuk lebih terlibat dalam keluarga (St John, 2005). Hasil ini didukung oleh penelitian yang dilakukan oleh Mira, et al (2012) di wilayah kerja Puskesmas Rakit Kulim Kabupaten Indragiri Hulu, bahwa rendahnya dukungan suami dalam pemberian ASI eksklusif bisa disebabkan karena suami yang sibuk bekerja sehingga menyarankan ibu untuk memberikan susu formula pada bayi 0-6 bulan.

\section{Dukungan Suami kepada Istri dalam Upaya Pemberian ASI}

Hasil penelitian ini menunjukkan bahwa sebanyak 41,7 \% ibu nifas primipara mendapatkan dukungan dari suami dalam pemberian ASI Eksklusif. Friedman dkk. (2003) menjelaskan bahwa dukungan suami memiliki empat fungsi yaitu dukungan informasi, dukungan penilaian, dukungan fisik atau instrumental, dan dukungan emosional. Dukungan informatif adalah suami berfungsi sebagai penerima dan penyebar informasi tentang semua informasi yang ada dalam kehidupan. Berdasarkan hasil penelitian bahwa sebanyak 52,8 \% ibu primipara mendapat dukungan informasi dari suami dalam upaya pemberian ASI. Dukungan informasi ini antara lain dinilai dengan suami mencari informasi tentang ASI Eksklusif, meberikan bacaan seperti buku dan majalah kepada ibu, suami ikut mengantar ibu periksa, suami mengingatkan ibu mengikuti anjuran tenaga kesehatan serta tidak melarang ibu bertanya tentang ASi kepada orang lain. Dukungan suami dalam mencari informasi tentang ASI Eksklusif pada penelitian ini sebanyak 58,3\% responden. Namun pada penelitian ini masih $11,1 \%$ suami yang melarang ibu bertanya kepada siapapun tentang pemberian ASI. Hasil penelitian ini berbeda dengan hasil penelitian Ratu Ummu di Puskesmas Pisangan menemukan sebanyak $100 \%$ ibu mendapat dukungan informasi dari suami.

Bentuk dukungan suami juga berupa dukungan penilaian yaitu bentuk dukungan suami sebagai identitas anggota dalam status keluarga yang menjadi sumber validator dengan tegas pembimbing dan bimbingan umpan balik dalam memecahkan masalah. Hasil penelitian menunjukkan pada penilaian sebanyak 38,9 \% responden mendapat dukungan penilaian dari suami. Temuan lain dari penelitian ini adalah masih terdapat 27,8 $\%$ suami yang menyarankan istri untuk memberi susu formula ketika jumlah ASI istri sedikit. Hasil ini didukung oleh penelitian yang dilakukan oleh Mira, et al (2012) di wilayah kerja Puskesmas Rakit Kulim Kabupaten Indragiri Hulu, rendahnya dukungan suami dalam pemberian ASI eksklusif bisa disebabkan karena suami yang sibuk bekerja sehingga menyarankan ibu untuk memberikan susu formula pada bayi 0-6 bulan.

Sebanyak 44,4, \% responden mendapatkan dukungan fisik dari suami dalam upaya pemberian ASI. Temuan lain dari penelitian ini menunjukkan pada penilaian fisik hanya $41,6 \%$ suami yang melakukan pekerjaan rumah tangga saat ibu sedang menyusui. Dukungan fisik adalah bentuk dukungan suami sebagai penyediaan materi yang dapat memberikan pertolongan langsung seperti pemberian uang, pemberian barang, makanan serta pelayanan. Membantu 
pekerjaan rumah tangga dapat dilakukan suami ketika istri sedang menyusui. Suami dapat bekerja sama dalam hal pengasuhan bayi dan pemberian ASI. Selama ibu menyusui, suami dapat mengambil alih pekerjaan rumah tangga, sehingga sesampainya di rumah ibu berkesempatan untuk memberikan ASI tanpa harus direpotkan lagi dengan pekerjaan rumah tangga.

Dukungan emosional suami adalah bentuk dukungan keluarga ataupun suami sebagai sebuah tempat yang nyaman, aman dan damai. Membantu secara psikologis dalam menstabilkan emosi dan mengendalikan diri, maka dari itu bentuk dukungannya adalah dengan cara memberikan motivasi dan peranan dalam mendengarkan semua keluhan-keluhan masalah yang sedang dihadapi ibu. Hasil penelitian mendapatkan sebanyak 38,9\% ibu primipara di Rumah Sakit Panti Wilasa Citarum Semarang mendapatkan dukungan emosional dari suami. Dalam penilaian dukungan emosional menunjukkan $50 \%$ suami memberi dukungan kepada istri agar tidak usah takut menyusui karena menyebabkan perubahan bentuk tubuh dan $50 \%$ suami tidak mendukung ibu menyusui karena akan terjadi perubahan bentuk tubuh. Hasil ini sesuai dengan penelitian Owens dalam Kemalasari (2009), mengungkapkan bahwa kurangnya dukungan suami dalam pemberian ASI eksklusif adalah karena menyusui menyebabkan ibu menjadi jelek, tidak menarik dan dapat menghambat atau meninggalkan hubungan seks antara suami dan istri. Hasil penelitian ini juga ditemukan hanya 33, 3\% suami yang memberikan suasana tenang saat ibu menyusui bayinya. Dukungan suami dalam menyediakan rasa nyaman pada ibu termasuk dalam dukungan emosional. Dukungan suami berupa perhatian kepada istri, menciptakan suasana nyaman bagi istri sehingga kondisi psikis ibu sehat. Pikiran ibu yang positif akan merangsang kontraksi otot sekeliling kelenjar susu (mammary alveoli) hingga mengalirkan ASI ke sinus lactiferous dan kemudian diisap oleh si bayi. Ternyata peran suami sangat penting karena memperlancar pemberian ASI yang bermakna bagi peningkatan mutu kehidupan anak, ironisnya kondisi ini tidak banyak dipahami oleh para suami. Hasil ini tidak sesuai dengan hasil penelitian Ratu Ummu di Puskesmas Pisangan didapatkan bahwa sebagian besar suami memberikan dukungan emosional sebesar $88,2 \%$.

\section{Hubungan Dukungan Suami Kepada Istri dengan Keberhasilan ASI Eksklusif ASI Eksklusif adalah pemberian air susu ibu saja sampai usia 6 bulan, tanpa} memberikan makanan atau cairan lain, keculai vitamin, mineral dan obat yang telah diizinkan (WHO, 2010). Hasil penelitian menunjukkan hanya 33,3\% ibu yang berhasil memberikan ASI Eksklusif selama 6 bulan kepada bayi, dan sebanyak 66,7 \% tidak berhasil memberikan ASI Eksklusif pada ibu primipara di Rumah Sakit Panti Wilasa Citarum Semarang. Hasil penelitian ini sesuai dengan hasil penelitian Ratu Ummu yang juga mendapatkan hasil hanya 8 orang $(23,5 \%)$ ibu primipara yang berhasil memberikan ASI Eksklusif, sedangkan 24 ibu primipara $(76,5 \%)$ ibu tidak berhasil memberikan ASI Eksklusif.

Berdasarkan uji statistik tersebut didapatkan hasil nilai $\rho$ value 0.03 ini berarti $\rho$ value lebih kecil dari taraf signifikan 5\% $(0.03<0.05)$ sehingga hasil yang di dapat $\mathrm{H}_{\mathrm{a}}$ diterima. Jadi, hasil analisis menunjukkan terdapat hubungan antara dukungan suami dalam upaya pemberian ASI dengan keberhasilan ASI Eksklusif di Rumah Sakit Panti Wilasa Citarum Semarang. Ibu yang mendapatkan dukungan suami lebih besar peluangnya untuk memberikan ASI eksklusif dibandingkan dengan ibu yang tidak mendapatkan dukungan suami. Seorang suami yang mengerti dan memahami manfaat ASI pasti akan membantu ibu mengurus bayi, termasuk menggantikan popok, memandikan bayi, dan memberikan pijatan pada bayi. Sementara ibu, berusaha fokus meningkatkan kualitas ASI-nya dengan mengonsumsi makanan bergizi seimbang dan melakukan pola hidup sehat (Roesli, 2008).

Hasil penelitian ini sejalan dengan hasil penelitian Retno Sulistiani (2016) dimana ada hubungan antara dukungan suami dengan pemberian ASI Eksklusif di Puskesmas Pakualaman Yogyakarta $(\mathrm{p}=0,02)$.

Berdasarkan tabel 12 hasil penelitian menunjukkan bahwa dari 15 ibu primipara yang mendapat dukungan dari suami, sebesar 8 orang $(53,4 \%)$ yang berhasil menyusui secara ASI Eksklusif. Hasil penelitian juga menunjukkan dari 21 ibu primipara yang tidak 
mendapat dukungan suami ada 4 orang $(19,1 \%)$ yang berhasil menyusui secara eksklusif. Dukungan suami mempunyai peran besar dalam keberhasilan memberikan ASI eksklusif. Semakin besar dukungan suami maka semakin besar juga peluang ibu untuk menyusui bayinya. Hal ini akan mempengaruhi kelancaran refleks pengeluaran ASI, karena reflek tersebut dipengaruhi oleh perasaan dan emosi ibu. Dukungan suami diperlukan untuk menghasilkan ketenangan, ketenteraman, dan kenyamanan ibu menyusui yang dapat meningkatkan produksi hormon oksitosin, sehingga dapat meningkatkan pemberian ASI. Reeves, dkk. (2012) menyatakan bahwa ibu menyusui karena mereka percaya ASI lebih sehat untuk bayi. Suami merupakan pemberi dukungan yang paling berpengaruh. Sistem pendukung itu sangat penting bagi ibu menyusui untuk mengambil keputusan memberi ASI pada bayi umur 0-6 bulan secara eksklusif. Suami dapat berperan dalam meningkatkan percaya diri ibu dalam memberikan ASI, kepercayaan diri ibu dapat meningkatkan produksi ASI.

\section{SIMPULAN DAN SARAN Simpulan}

Ibu primipara di Rumah Sakit Panti Wilasa Citarum Semarang yang mendapat dukungan suami secara aktif dalam pemberian ASI sebesar $41,7 \%$, meliputi dukungan emosional sebesar 38,9\%, dukungan informasi sebesar 52,8 \%, dukungan fisik sebesar 44,4 $\%$ dan dukungan penilaian sebesar 38,9\%. Ibu primipara di Rumah Sakit Panti Wilasa Citarum Semarang yang berhasil memberikan ASI Eksklusif sebesar 33,3\%. Ada hubungan dukungan suami dalam upaya pemberian ASI dengan keberhasilan ASI Eksklusif di Rumah Sakit Panti Wilasa Citarum Semarang $(\mathrm{p}=0.03)$

\section{Saran}

Suami berperan penting dalam pemberian ASI eksklusif, oleh sebab itu kepada Rumah Sakit Panti Wilasa Citarum bisa meningkatkan dukungan suami terhadap pemberian ASI melalui program pembentukan kelas ayah dalam upaya persiapan menjadi ayah ASI serta suami juga dijadikan sasaran dalam penyuluhan ASI.

\section{DAFTAR PUSTAKA}

1. Arora S, Junkin CM, Wherer J, Kuhn P. 2000. Mayor Factor Inluencing Breastfeeding Rates: Mother's Perception Of Father's Attitude And Milk Supply. Pediatrics [serial online]. [diunduh 1 November 2019]. 106(5): e67. tersedia dari: http://www.pediatrics.org/cgi/content/f ull/106/5/e67

2. Badan Kependudukan dan Keluarga Berencana Nasional. 2018. Survei Demografi dan Kesehatan Indonesia 2017. Badan Kependudukan dan Keluarga Berencana Nasional. Jakarta.

3. Destriatania S. 2010. Hubungan antara Pengetahuan dan Sikap Ayah terhadap Praktik Inisiasi Menyusu Segera dan Pemberian ASI Eksklusif Diwilayah Urban Jakarta Selatan. Tesis. Program Studi Ilmu Kesehatan Masyarakat Fakultas Kesehatan Masyarakat Universitas Indonesia Jakarta.

4. Dinas Kesehatan Kota Semarang. 2018 . Profil Kesehatan Kota Semarang. Dinas kesehatan Kota Semarang. Semarang.

5. Friedman, M, Bowden, V.R., \& Jones, E.G. 2003. Family Nursing Research, Theory and Practice. New Jersey: Prentice Hall.

6. Hani RU. 2014. Hubungan Dukungan Suami terhadap Keberhasilan Pemberian ASI Eksklusif pada Ibu Primipara di Wilayah Puskesmas Pisangan. Skripsi. Program Studi Ilmu Keperawatan Fakultas Kedokteran dan Ilmu Kesehatan. Universitas Islam Negeri Syarif Hidayatullah Jakarta. Jakarta.

7. Kemalasari, 2009. Pengaruh Partisipasi Suami terhadap Pemberian ASI Eksklusif di Kabupaten Langkat. Tesis, Program Megister Konsentrasi Administrasi Kebijakan Kesehatan, Program Studi Administrasi dan Kebijakan Kesehatan, Program Pascasarjana USU. Medan

8. Kemenkes. 2012. Peraturan Pemerintah RI. Peraturan Pemerintah RI Nomor 33 Tahun 2012 tentang 
Pemberian Air Susu Ibu Eksklusif. Kemenkes.Jakarta.

9. Kemenkes. 2011. Panduan Kader Posyandu. Dirjen Pemberdayaan Masyarakat dan Desa. Jakarta.

10. Khasanah N. 2011. ASI atau Formula. Flash Book. Jakarta.

11. Liubai LI, Sujun LI. Feeding Practices Of Infant And Their Correlates In Urban Areas of Beijing, China. Pediatrics International. 2003; 45: 400-6.

12. Mira,et al.2012. Hubungan Dukungan Suami terhadap Motivasi Ibu Memberi ASI pada Bayi 0-6 Bulan.

13. Ramadani M, Hadi EN. Dukungan Suami dalam Pemberian ASI Eksklusif di Wilayah Kerja Puskesmas Air Tawar Kota Padang, Sumatera Barat. KESMAS, Jurnal Kesehatan Masyarakat Nasional Vol. 4, No. 6, Juni 2010, 269-274

14. Reeves, C., Close, F.T., Simmons, M.C., \& Hollis, A.L. (2012). Social Support Indicators That Infl Uence Breastfeeding Decision In Mothers Of North Fl Orida. Florida Public Health Review, 3, 1-7.

15. Roesli U.2008. Mengenal ASI ekslusif. Pustaka Bunda.Jakarta.

16. Roesli U.2012. Inisiasi Menyusui Dini Plus ASI Eksklusif. Pustaka Bunda Grup Puspa Swara. Jakarta.

17. Saleha S. 2009. Asuhan Kebidanan pada Masa Nifas. Salemba Medika. Jakarta.

18. St John. Meeting The Challenge Of New Fatherhood During The Early Week. Journal ObstetricGynecol Neonatal Nurs. 2005; 34 (2): 180-9.

19. Sulistiani R. 2016. Pengaruh Dukungan Suami Terhadap Pemberian ASI Eksklusif di wilayah Kerja Puskesmas Pakualam Kota Yogyakarta. Karya Tulis Ilmiah. Prodi Diploma IV Kebidanan Universitas Sebelas Maret Surakarta. Surakarta.

20. Suradi R, Tobing HKP. 2007. Bahan Bacaan Manajemen Laktasi. Cetakan ke-3. Program Manajemen Laktasi Perkumpulan Perinatologi Indonesia. Jakarta.
21. Yuliarti N. 2010. Keajaiban ASI Makanan Terbaik untuk Kesehatan, Kecerdasan, dan Kelincahan Si Kecil. CV. ANDI. Yogyakarta. 